\title{
Evaluation of Dynamic Hyperinflation with Negative Expiratory Pressure Method in Patients with Chronic Obstructive Pulmonary Disease
}

\author{
(D) Hande İkitimur ${ }^{1}$, (D) Gülfidan Uzan² \\ 1 Biruni University Faculty of Medicine, Department of Pulmonary Diseases, Istanbul, Turkey \\ ${ }^{2}$ Haseki Training And Research Hospital, Clinic of Pulmonary Diseases, İstanbul, Turkey
}

\section{Abstract}

Objective: Chronic Obstructive Pulmonary disease (COPD) is a disease characterized by progressive airflow limitation, which is not fully reversible. Expiratory flow limitation (EFL) is the most common cause of dynamic hyperinflation $(\mathrm{DH})$ and increased respiratory workload in COPD. In our study, the relationship between negative expiratory pressure (NEP) and all pulmonary function tests, especially inspiratory capacity (IC), was investigated in the examination of DH in COPD patients.

Methods: Thirty four COPD patients with a mean forced expiratory volume in one second (FEV1) of $38.9 \pm 12.7 \%$ and 15 healthy subjects were included in the study. Pulmonary function tests and NEP were performed in all COPD patients.

Results: In 16 COPD patients (47.1\%), EFL was positive with NEP. When pulmonary function tests of EFL positive and EFL negative patients were compared, significant differences were found only in obstruction parameters such as FEV1 and forced expiratory flow 25-75, but no difference was found with lung volumes and diffusion test. However, there was a statistically significant correlation between IC and FVC ( $\mathrm{mL}$ and \% predicted), FEV1 (\% predicted) and lung volumes ( $\mathrm{mL}$ and \% predicted) and FRC $(\mathrm{mL})(\mathrm{p}<0.05)$. There was a negative but statistically insignificant correlation between IC and presence of flow limitation $(p>0.05)$.

Conclusion: We think that NEP application in COPD patients does not provide additional information about DH and that IC is the best predictor of DH.

Keywords: Chronic Obstructive Pulmonary disease, inspiratory capacity, negative expiratory pressure

\section{INTRODUCTION}

Chronic Obstructive Pulmonary disease (COPD) is an inflammatory disease caused by various harmful particles and gases, and is characterized by progressive airflow limitation that is not fully reversible. Airflow limitation in COPD develops as a result of small airway disease and parenchymal destruction. While chronic inflammation leads to remodeling and narrowing of the small airways, the decrease in elastic recoil as a result of parenchymal damage makes it difficult to maintain the patency of the airways during expiration (1). In patients with COPD, the delay in lung emptying due to decreased expiratory flow during spontaneous breathing prevents the lungs from passively reaching the functional residual capacity (FRC) level before the next inspiration. As a result, the end-expiratory lung volume exceeds the FRC level. Pulmonary volume increases in COPD due to reduced elastic recoil and airway resistance. This leads to a new equilibrium at a higher level than FRC at the end of the expiration. This phenomenon is called dynamic hyperinflation (DH) (2). In COPD, pulmonary function tests (PFT) are the most commonly used laboratory methods in the diagnosis, evaluation of disease progression and prognosis and severity of the disease, and monitoring the treatment response (3). Spirometric examination is mandatory to confirm the diagnosis of COPD. It has been reported that inspiratory capacity (IC) is guiding for demonstrating the presence of dynamic collapse in the respiratory tract in COPD (3). IC is the volume of gas that can be inspired following a normal, quiet expiration. It includes tidal volume (TV) and inspiratory reserve volume. It constitutes approximately $75 \%$ of vital capacity. In recent studies, it has been 
shown that IC is an important parameter in demonstrating the presence of $\mathrm{DH}$ in the respiratory tract in $\operatorname{COPD}(4,5)$. The most important change that can be detected in spirometry in COPD is expiratory flow limitation (EFL). Negative expiratory pressure (NEP) technique is one of the simplest ways to demonstrate EFL, which is the most important cause of DH. The NEP technique usually involves applying a negative pressure around $-5 \mathrm{~cm}$ $\mathrm{H}_{2} \mathrm{O}$ into the mouth during tidal expiration and comparing the resulting flow-volume (F-V) loop with the previously made control expiratory F-V loop. In COPD patients, NEP technique can be applied during mechanical ventilation, exercise, dyspneic and orthopneic state, before and after bronchodilatation, and in different positions. Maximal expiratory flow can be achieved even at rest in conditions with airflow limitations, such as COPD. In patients with COPD, it is seen that the volume of gas remaining in the lungs increases at the end of expiration, especially during exercise. As a result, the expiratory reserve volume increases, the inspiratory reserve volume decreases, and the IC decreases. This is due to the collapse of the peripheral airways and increased expiratory reserve volume due to increased dynamic collapse during exercise. Increase in TV during exercise can reach up to IC value in COPD patients. In addition, flow velocities during TV can reach the flow velocities at maximal expiration loop. The reflection of this in the F-V loop is that the TV curve plotted during the exercise coincides with the maximal expiration curve, thus EFL being positive. Presence of EFL in COPD patients leads to $\mathrm{DH}$, increased respiratory work, impaired inspiratory muscle function and progressive dyspnea (4-7). In this study, we aimed to investigate the relationship between NEP and PFT and lung volumes in the examination of $\mathrm{DH}$ in patients with COPD.

\section{METHODS}

Thirty four stable patients with COPD at stage 2 and 3 (1) and 15 healthy subjects without smoking history and respiratory disease were included in the study. Patients with COPD were on inhaled long-acting beta-agonists, anticholinergic, inhaler steroid and oral theophylline with inhaled short-acting beta-agonists. Stable period was defined as not having an acute exacerbation of COPD until four weeks prior to enrollment. According to this definition, the presence of two of the three criteria, including worsening in dyspnea, increase in purulence or amount of sputum, makes the diagnosis of COPD exacerbation clinically. Patients with known pulmonary disease other than COPD and who had received oral corticosteroid treatment in the last two months were excluded from the study. The control group was selected from the patients who applied to the chest diseases outpatient clinic and did not have any pathology in their examinations. Informed consent form was obtained from all subjects at the beginning of the study. All patients in the COPD and control groups were evaluated by PFT (spirometer, lung volumes) in sitting position and EFL examination by NEP in the respiratory laboratory. The study was approved by Ethics Board of Department of Chest Disesase (1724-2004).

\section{Pulmonary Function Tests}

Spirometric examinations were performed in the respiratory laboratory using Sensor Medics Vmax Series 22. Forced spirometric tracing was obtained by prompting the patient to inspire to the level of total lung capacity, followed by rapid and forced ventilation. The curve was plotted at least three times while the nose was closed and the maximum FVC and forced expiratory volume in one second (FEV1) values of the three curves were used in our study. Total lung volume and residual volume measurements were made using Nitrogen Washout method (8).

\section{Negative Expiratory Pressure}

In our study, NEP method was used to detect EFL. The tools required for the application of this method are as follows:

- Pneumatograph

- Differential pressure transducer

- Negative pressure generating device

- Data collection system

A plastic mouthpiece is connected to the $T$ tube and pneumotograph. One end of the $T$ tube is open to the atmosphere. The other end is exposed to the negative pressure created by the venturi apparatus or vacuum generator by means of a valve (solenoid valve, Hans Rudolph valve). When the valve is opened, NEP is applied to the airway. Airway flow $\left(\mathrm{V}^{\circ}\right)$ is measured by pneumotograph, while airway opening pressure is simultaneously measured by the side port of the mouthpiece. Volume $(V)$ is obtained from numerical integration of flow signals in data acquisition systems. The F-V loop obtained by NEP is overlaid with the F-V loop obtained by the previous normal respiration. Data analysis is performed by visual evaluation of two F-V loops (9). In our study, a Micro NEP brand NEP device was used (Micro Medical Ltd. Kent, UK).

The results obtained from the NEP technique are interpreted in three ways:

- No flow limitation

- Flow limitation during one part of expiration 
- Limited flow throughout expiration. Flow limitation of expiration is given as a percentage of control TV \% (9).

As shown in Figure 1, if NEP application leads to increased flow through the entire control VT, flow is not limited (NEP example, left panel). On the contrary, if the F-V loop formed during expiration with NEP intersects with some or all of the control F-V loop, the patient has EFL (NEP example, middle and right panel) (Figure 1).

\section{Statistical Analysis}

SPSS (Statistical Package for Social Sciences, SPSS Inc., Chicago, Illinois, USA) for Windows 10.0 was used for data analysis. The determination of the number of samples in our study was based on the studies in the literature in which the NEP method was examined in COPD cases. The post hoc power analysis at the end of the study revealed a $100 \%$ power for FVC with $95 \%$ confidence interval. Normality of the data was evaluated by KolmogorovSmirnov test. Mann-Whitney U test was used to compare the parameters. Pearson method was used for correlation analysis. The values were expressed as mean \pm standard deviation, and non-normally distributed data were expressed as median and interquartile range 25-75. $\mathrm{P}<0.05$ was considered statistically significant.

\section{RESULTS}

Demographic characteristics of the patients are shown in Table 1. Regarding mean ages of the groups, no statistically significant difference was found between patient and control groups $(p>0.05)$.

Spirometric values of patient and control groups are presented in Table 2 and lung volumes are presented comparatively in Table 3. NEP technique was applied to all participants. EFL was not detected in any of the subjects in the control group. EFL was positive in 16 COPD patients (47.1\%). When the EFL

\begin{tabular}{|c|c|c|}
\hline & COPD group & Control group \\
\hline Number of cases (F, M) & $34(2 \mathrm{~F}, 32 \mathrm{M})$ & $15(2 \mathrm{~F}, 13 \mathrm{M})^{*}$ \\
\hline Age (years) & $66.3 \pm 7.9$ & $66.7 \pm 7.7^{* * *}$ \\
\hline Disease duration (years) & $7.97 \pm 5$ & - \\
\hline Smoking (pack/year) & $57.6 \pm 29.7$ & - \\
\hline $\begin{array}{l}\text { Number of patients who stopped } \\
\text { smoking }\end{array}$ & 31 & - \\
\hline Smoking cessation period (years) & $4.1 \pm 4.7$ & - \\
\hline \multicolumn{3}{|c|}{$\begin{array}{l}\text { COPD: Chronic Obstructive Pulmonary disease, F: Female, M: Male } \\
{ }^{*} p>0.05,{ }^{* *} p>0.05\end{array}$} \\
\hline
\end{tabular}

was expressed as a percentage of TV, the mean EFL value was $31.44 \pm 38 \%$. The study group was divided into two groups as EFL positive and negative, and the variables between the two groups were examined. There was no statistically significant difference between the two groups in terms of age, amount of smoking and disease duration ( $p>0.05)$. Spirometry values of the group with positive and negative EFL are presented in Table 4 , and a statistically significant difference was found between FEV1 (\%) and forced expiratory flow (FEF) 25-75\% (\%) values. The comparison of lung volumes of the group with and without EFL is shown in Table 5 and no statistically significant difference was found between the two groups. Table 6 shows the correlation coefficients of IC values measured in the COPD group with age, disease duration, presence of EFL, PFT and lung volumes. As shown in the Table 6, significant correlations were found

\begin{tabular}{|c|c|c|}
\hline $\begin{array}{l}\text { Pulmonary function } \\
\text { tests }\end{array}$ & Patient group & Control group \\
\hline $\mathrm{FVC}(\mathrm{mL})$ & $2365 \pm 643$ & $3975 \pm 629 *$ \\
\hline FVC (\%) & $72.1(61.1-81.2)$ & $102.3(94.6-110.2)^{*} \mathrm{~T}$ \\
\hline FEV1 (mL) & $1001 \pm 300$ & $3258 \pm 551^{*}$ \\
\hline FEV1 (\%) & $38.9 \pm 12.7$ & $104.3 \pm 13.3^{*}$ \\
\hline FEV1/FVC (\%) & $42.8 \pm 7.6$ & $79.7 \pm 5.2^{*}$ \\
\hline FEF \%25-75 (L/sn) & $0.25(0.11-0.47)$ & $3.4(2.46-4.8)^{*} \mathrm{~T}$ \\
\hline FIV1 (mL) & $1800(1212-2500)$ & $3480(2600-4300)^{*} \mathrm{~T}$ \\
\hline \multicolumn{3}{|c|}{$\begin{array}{l}\text { FVC: Forced vital capacity, FEV1: Forced expiratory volume in one second, FEF } \\
\text { Forced expiratory flow, FIV1: Forced inspiratory volume in one } \\
\text { * } p<0.000 \text {, } \mathrm{F} \text { : Mann-Whitney U test used }\end{array}$} \\
\hline
\end{tabular}

Table 3. Lung volumes of patient and control groups

\begin{tabular}{|c|c|c|}
\hline Lung volumes & Patient group & Control group \\
\hline $\mathrm{TLC}(\mathrm{mL})$ & $6610 \pm 1896$ & $6157 \pm 776$ \\
\hline TLC (\%) & $109.5 \pm 26.3$ & $97.5 \pm 10 *$ \\
\hline $\mathrm{RV}(\mathrm{mL})$ & 3980 (2504-4904) & $2261(1724-2803)^{* *} \mathrm{f}$ \\
\hline RV (\%) & $169.1 \pm 50.9$ & $102.3 \pm 13.6^{* *}$ \\
\hline RV/TLC (\%) & $59.6 \pm 8.9$ & $35.2 \pm 3.3 * *$ \\
\hline $\mathrm{VC}(\mathrm{mL})$ & $2604 \pm 747$ & $3919 \pm 554 * *$ \\
\hline VC (\%) & $74.4 \pm 21.9$ & $96.8 \pm 10.7^{* *}$ \\
\hline IC (mL) & $1885 \pm 499$ & $3023 \pm 723 * *$ \\
\hline $\mathrm{FRC}(\mathrm{mL})$ & $4699 \pm 1643$ & $2951 \pm 539 * *$ \\
\hline FRC (\%) & $140.5 \pm 42.6$ & $94.6 \pm 14.8^{* *}$ \\
\hline $\mathrm{ERV}(\mathrm{mL})$ & 705 (312-1115) & $702(524-1064) \mathrm{F}$ \\
\hline \multicolumn{3}{|c|}{$\begin{array}{l}\text { TLC: Total lung capacity, RV: Residual volume, VC: Vital capacity, } \\
\text { capacity, FRC: Functional residual capacity, ERV: Expiratory reserve } \\
\text { The data in parentheses are median and interquartile range } 25-75 \\
{ }^{*} \mathrm{p}<0.05,{ }^{* *} \mathrm{p}<0.000 \text {, F: Mann-Whitney U test used }\end{array}$} \\
\hline
\end{tabular}



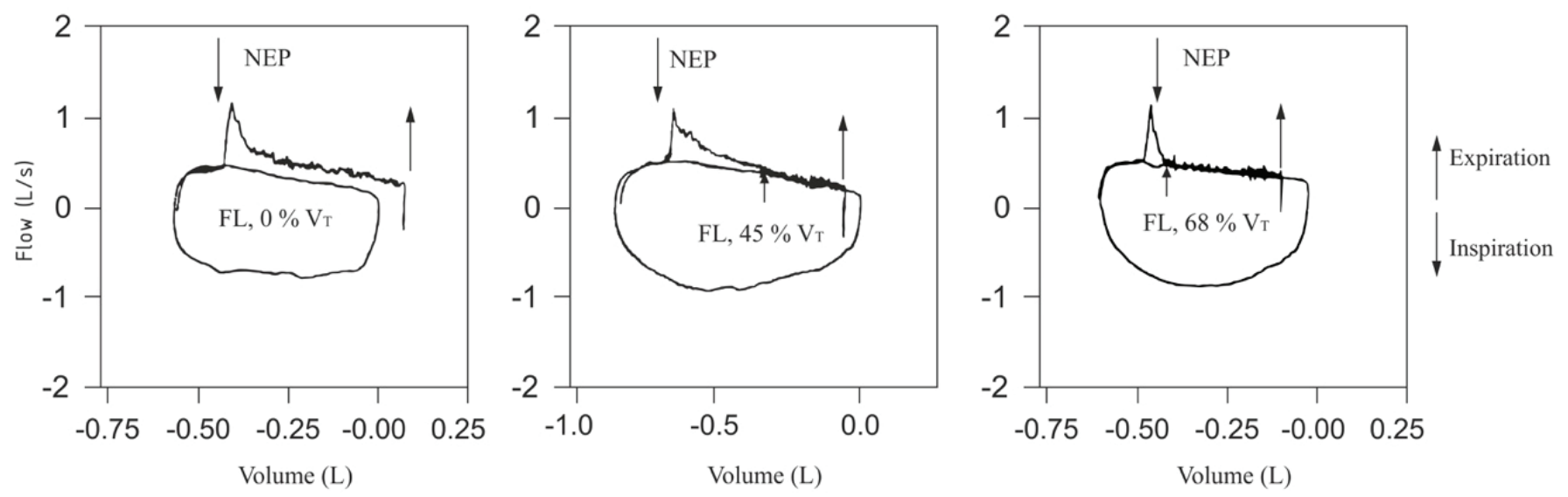

Figure 1. Negative expiratory pressure examples of cases with and without flow limitation (5)

NEP: Negative expiratory pressure

\begin{tabular}{|c|c|c|}
\hline Pulmonary function tests & EFL negative & EFL positive \\
\hline $\mathrm{FVC}(\mathrm{mL})$ & $2459.4 \pm 623.6$ & $2260.6 \pm 6669.6$ \\
\hline FVC (\%) & $76.7(51.2-98.3)$ & $68.2(49.2-87.3) \mathrm{T}$ \\
\hline FEV1 (mL) & $1080 \pm 326.5$ & $913.7 \pm 248.3$ \\
\hline FEV1 (\%) & $43.5 \pm 14.5$ & $33.8 \pm 8^{*}$ \\
\hline FEV1/FVC (\%) & $44.6 \pm 8.8$ & $40.9 \pm 5.5$ \\
\hline FEF $25-75 \%(\mathrm{~L} / \mathrm{s})$ & $0.37(0.22-0.53)$ & $0.29(0.21-0.49) \mathrm{T}$ \\
\hline FEF $25-75 \%(\%)$ & $12.8(7.3-16.4)$ & $9.4(6.4-13.4)^{*} \mathrm{~T}$ \\
\hline \multicolumn{3}{|c|}{$\begin{array}{l}\text { FVC: Forced vital capacity, FEV1: Forced expiratory volume in one second, FEF } \\
\text { Forced expiratory flow } \\
\text { The data in parentheses are median and interquartile range } 25-75 \\
{ }^{*} \mathrm{p}<0.05 \text {, } \mathrm{F} \text { : Mann-Whitney U test used }\end{array}$} \\
\hline
\end{tabular}

Table 5. Pulmonary function test values of the group with negative and positive expiratory flow limitation and positive group

\begin{tabular}{|c|c|c|}
\hline Pulmonary volumes & EFL negative & EFL positive \\
\hline $\mathrm{TLC}(\mathrm{mL})$ & $6920 \pm 1605$ & $6223 \pm 2219 *$ \\
\hline TLC (\%) & $116.3 \pm 20.4$ & $101 \pm 31.1^{*}$ \\
\hline $\mathrm{RV}(\mathrm{mL})$ & 4276 (3325-5135) & $3620(2704-4226)^{*} \mathrm{~T}$ \\
\hline RV (\%) & $180.3 \pm 39.6$ & $155.1 \pm 61.2^{*}$ \\
\hline RV/TLC (\%) & $62 \pm 6.6$ & $56.5 \pm 10.6^{*}$ \\
\hline $\mathrm{FRC}(\mathrm{mL})$ & $4954 \pm 1385$ & $4382 \pm 1935^{*}$ \\
\hline FRC (\%) & $148.4 \pm 33.4$ & $130.6 \pm 51.7^{*}$ \\
\hline IC (mL) & $1921 \pm 475$ & $1843 \pm 543^{*}$ \\
\hline \multicolumn{3}{|c|}{$\begin{array}{l}\text { TLC: Total lung capacity, RV: Residual volume, IC: Inspiratory capacity, FRC: } \\
\text { Functional residual capacity, EFL: Expiratory flow limitation } \\
\text { "p }>0.05 \text {, F: Mann-Whitney U test used } \\
\text { The data in parentheses are median and interquartile range } 25-75\end{array}$} \\
\hline
\end{tabular}

between IC and PFT and lung volumes. However, a negative but not statistically significant correlation was found between IC and EFL.

\begin{tabular}{|c|c|}
\hline Parameters & Correlation coefficients ( $r$ ) \\
\hline Age (years) & 0.242 \\
\hline Disease duration (years) & -0.373 \\
\hline Presence of expiratory flow limitation & -0.202 \\
\hline FVC (\%) & $0.592^{* * *}$ \\
\hline FEV1 (\%) & $0.519^{* *}$ \\
\hline FEV1 /FVC (\%) & 0.047 \\
\hline PEF (\%) & $0.666^{* * *}$ \\
\hline TLC (\%) & $0.573^{* *}$ \\
\hline $\mathrm{VC}(\mathrm{mL})$ & $0.797^{* * *}$ \\
\hline $\mathrm{VC}(\%)$ & $0.599^{* * * *}$ \\
\hline $\mathrm{FRC}(\mathrm{mL})$ & $0.438^{*}$ \\
\hline $\mathrm{RV}(\mathrm{mL})$ & $0.484^{*}$ \\
\hline $\mathrm{RV}(\%)$ & $0.429^{*}$ \\
\hline \multicolumn{2}{|c|}{$\begin{array}{l}\text { FVC: Forced vital capacity, FEV1: Forced expiratory volume in one second, PEF: Peak } \\
\text { expiratory flow, VC: Vital capacity, TLC: Total lung capacity, RV: Residual volume } \\
\text { Pearson correlation analysis was used } \\
{ }^{*} p<0.05,{ }^{* *} p<0.01,{ }^{* * * *} p<0.001\end{array}$} \\
\hline
\end{tabular}

\section{DISCUSSION}

The main pathophysiological point of COPD is the presence of EFL. The most important cause of EFL is DH and increased respiratory workload. It has been shown that $\mathrm{IC}$ is the best predictor for reflecting the presence of $\mathrm{DH}$ in the respiratory tract, especially in studies evaluating exercise intolerance. In recent years, the use of IC in place of FEV1 has also been recommended to evaluate the efficacy of bronchodilator therapy $(10,11)$. One of the simplest ways to show EFL, which is the most important cause of $\mathrm{DH}$, is the implementation of NEP. In our study, 16 (47.1\%) of 34 patients with moderate and severe COPD had positive EFL in sitting position and 18 (52.9\%) were EFL negative. 
NEP application of two COPD cases with and without EFL is shown in Figure 2 and Figure 3. Koulouris et al. (12) applied NEP in 26 ambulatory COPD patients with a mean FEV1 of $60 \pm 22 \%$ and found EFL negative in seven patients (26.9\%). Eltayara et al. (13) found that EFL was negative in 26 cases (22.2\%) after the application of NEP in 117 patients with stable COPD, including 75 male and 42 female patients. In both studies, NEP was performed in the same patient in both sitting and supine positions. In both studies, no flow limitation was detected in both sitting and supine positions of the cases with negative EFL. In our study, since the application of NEP was performed only in the sitting position, the rate of negative EFL was found to be higher when compared with the literature. In two studies that examined the EFL by NEP only in the sitting position in the literature, the rates of positive EFL were found to be high as in our study. Positive EFL rate was $55.7 \%$ in the study conducted by Diaz et al. (14) and $61.1 \%$ in the study conducted by Tantucci et al. (15). In our study, when all PFT of the patients with positive and negative EFL were compared, only FEV1\% predicted and FEF $25-75 \%$ predicted were found to be statistically significantly different $(p<0.05)$. Studies in the literature have shown that FEV1\% predicted is significantly lower in COPD patients with positive EFL $(13,16)$.

SuperSpiro Nep Flow GRAPH

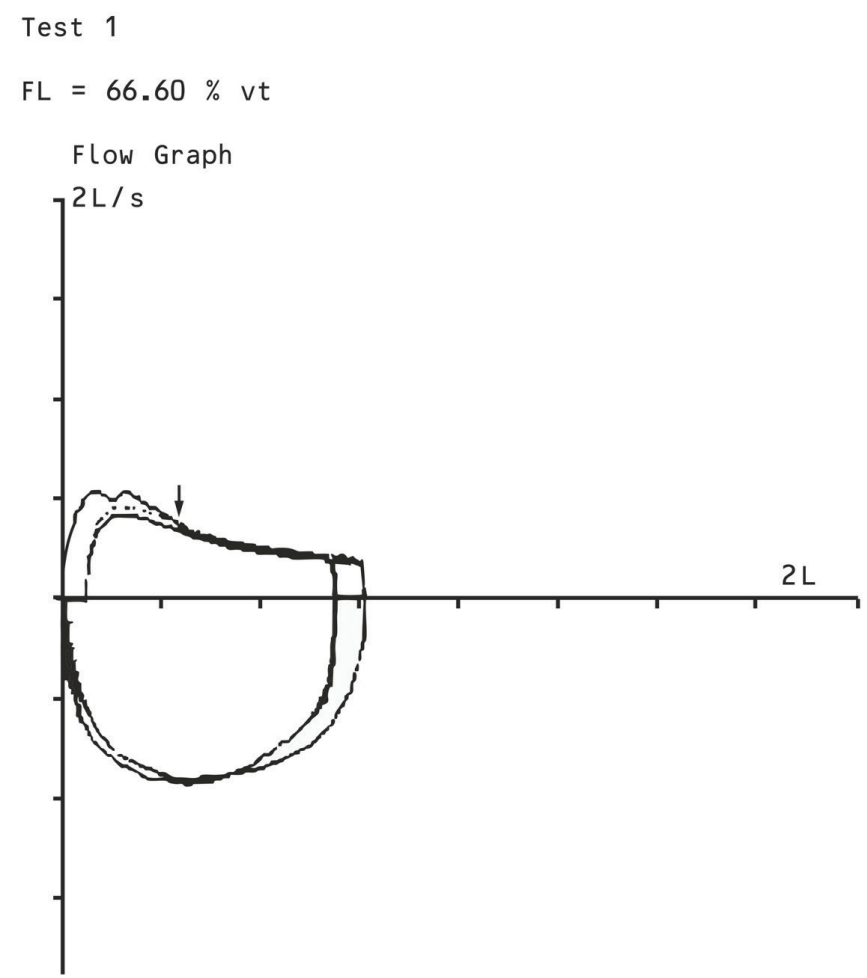

Figure 2. Negative expiratory pressure application of Chronic Obstructive Pulmonary disease patient with expiratory flow limitation
By examining the presence of EFL by using NEP method, information about DH can be obtained. In most of the studies on this subject, the presence of EFL in COPD patients was found to be significantly correlated with increased lung volumes. Koulouris et al. (16) found statistically significant difference in total lung capacity (TLC) \%, RV\%, RV/TLC, FRC\% values, while Diaz et al. (17) found statistically significant difference in other parameters except TLC\%. Boni et al. (18) found no significant difference in lung volumes between the groups with and without EFL, as in our study (14).

In recent studies, the importance of IC, which is a new parameter that correlates with dyspnea, has been emphasized in assessing the efficacy of pharmacological and surgical treatment in patients with COPD, identifying physiological changes during exercise (3). In our study, the relationship of IC with other lung volumes and NEP was evaluated in the evaluation of DH. There was a statistically significant correlation between IC and airway obstruction parameters such as FVC\% predicted, FEV1\% predicted and peak expiratory flow \% predicted $(p>0.05)$. Diaz et al. (17) Tantucci et al. (14) and Koulouris et al. (16) found a statistically significant negative correlation between IC and the presence

SuperSpiro Nep Flow GRAPH

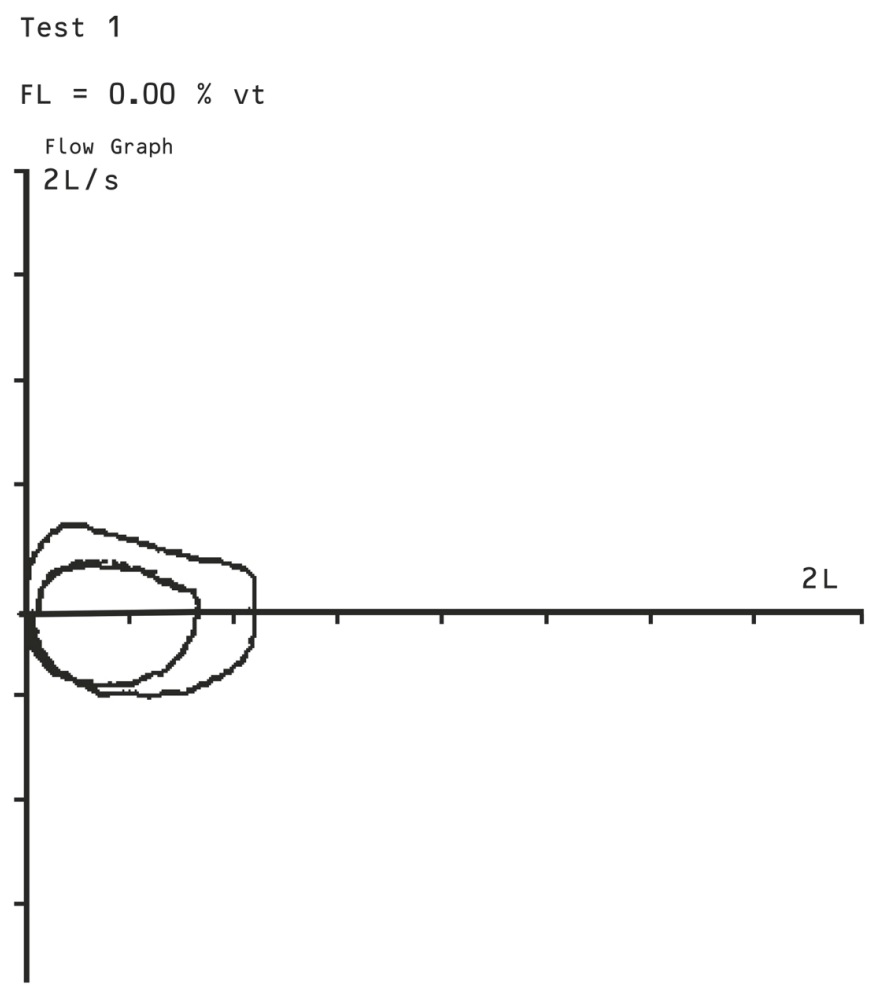

Figure 3. Negative expiratory pressure application of Chronic Obstructive Pulmonary disease patient without expiratory flow limitation 
of EFL. In our study, a negative but not statistically significant correlation was found. The presence of the relationship between IC and EFL in COPD patients shows the importance of NEP method in the determination of $\mathrm{DH}$. It reveals the widespread use of NEP, which is an inexpensive, practical and easy to use method for the detection of DH in COPD patients. In our study, TLC, FRC, VC and RV values in both $\mathrm{mL}$ and \% predicted values were correlated with IC as in the study by Diaz et al. (17).

\section{CONCLUSION}

In conclusion, we demonstrated that the examination of EFL by NEP method in COPD patients did not provide additional information about DH. We can say that IC is the best predictor of $\mathrm{DH}$.

\section{Ethics}

Ethics Committee Approval: The study was approved by Ethics Board of Istanbul University Cerrahpaşa Faculty of Medicine, Department of Chest Disesase (approval no: 1724-2004).

Informed Consent: Informed consent has been taken from all the patients.

Peer-review: External and internal peer-reviewed.

\section{Authorship Contributions}

Concept: H.i., Design: H.I., Data Collection or Processing: H.i., Analysis or Interpretation: H.I., Literature Search: H.I., Writing: H.I., G.U.

Conflict of Interest: No conflict of interest was declared by the authors.

Financial Disclosure: The authors declared that this study

received no financial support.

\section{REFERENCES}

1. Global Initiative For Chronic Obstructive Lung Disease. Global Strategy For The Diagnosis, Management, And Prevention of Chronic Obstructive Pulmonary Disease NHLBI/WHO Workshop Report. U.S. Department of Health and Human Services. Public Health service. National Institutes of Health. National Heart, Lung, and Blood Institute. NIH Publication No. 2701. April 2001.
2. Corne S, Anthonisen NR. Lung-function testing in chronic obstructive pulmonary disease. In: Voelkel NF, MacNee W editors. Chronic obstructive lung disease. Hamilton, BC Decker Inc. 2002:257-69.

3. O'Donnell DE, Lam M, Webb KA. Measurement of symptoms, lung hyperinflation and endurance during exercise in chronic obstructive pulmonary disease. Am J Respir Crit Care Med 1998;158:1557-65.

4. O'Donnell DE, Lam M, Webb KA. Measurement of symptoms, lung hyperinflation and endurance during exercise in chronic obstructive pulmonary disease. Am J Respir Crit Care Med 1997;155.

5. Milic-Emil J. Expiratory flow limitation. Chest 2000;117:2195-235.

6. Baydur A, Milic-Emili J. Expiratory flow limitation during spontaneous breathing: comparison of patients with restrictive and obstructive respiratory disorders. Chest 1997;112:1017-23.

7. Murariu C, Ghezzo H, Milic-Emili J, Gautier H. Exercise limitation in obstructive lung disease. Chest 1998;114:965-8.

8. American Thoracic Society: Standardization of spirometry-1994 update. Am J Respir Crit Care Med 1995;152:1107-36.

9. Koulouris NG. Negative expiratory pressure: a new tool. Monaldi Arch Chest Dis 2002;57:69-75.

10. O'Donnell DE, Revill SM, A Webb K. Dynamic hyperinflation and exercise intolerance in chronic obstructive pulmonary disease. Am J Respir Crit Care Med 2001;164:770-7.

11. O'Donnell DE. Assessment of bronchodilator efficacy in symptomatic COPD is spirometry useful? Chest 2000;117:42-7.

12. Koulouris NG, Dimopoulou I, Valta P, Finkelstein R, Cosio MG, Milic-Emili J. Detection of expiratory flow limitation during exercise in COPD patients. J Appl Physiol 1997;82:723-31.

13. Eltayara L, Becklake MR, Volta CA, Milic-Emili J. Relationship between choronic dyspnea and expiratory flow limitation in patients with choronic obstructive pulmonary disease. Am J Respir Crit Care Med 1996;154:1726-34.

14. Diaz O, Villafranca C, Ghezzo H, Borzone G, Leiva A, Milic-Emil J, et al. Role of inspiratory capacity on exercise tolerance in COPD patients with and without tidal expiratory flow limitation at rest. Eur Respir J 2000;16:269-275.

15. Tantucci C, Duguet A, Similowski T, Zelter M, Derenne JP, Milic-Emili J. Effect of salbutamol on dynamic hyperinflation in choronic obstructive pulmonary disease patients. Eur Respir J 1998;12:799-804.

16. Koulouris NG, Valta P, Lavoie A, Corbeil C, Chassé M, Braidy J, et al. A simple method to detect expiratory flow limitation during spontaneous breathing. Eur Respir J 1995;8:306-13.

17. Diaz O, Villafranca C, Ghezzo H, Borzone G, Leiva A, Milic-Emil J, Lisboa C, et al. Role of inspiratory capacity on exercise tolerance in COPD patients with and without tidal expiratory flow limitation at rest. Eur Respir J 2000;16:26975

18. Boni E, Corda L, Franchini D, Chiroli P, Damiani GP, Pini L. Volume effect and exertional dyspnea after bronchodilator in patients with COPD with and without expiratory flow limitation at rest. Thorax 2002;57:528-32. 